\title{
Tribological Properties of the Lubricant Containing Titanium Dioxide Nanoparticles as an Additive
}

\author{
Filip Ilie ${ }^{1, *,+}$ and Cristina Covaliu ${ }^{2, \dagger}$ \\ 1 Department of Machine Elements and Tribology, Polytechnic University of Bucharest, \\ 313 Spl. Independentei, 060042 Bucharest, Romania \\ 2 Department of Biotechnical Systems, Polytechnic University of Bucharest, 313 Spl. Independentei, \\ 060042 Bucharest, Romania; cristina_covaliu@yahoo.com \\ * Correspondence: ilie.filip@yahoo.com or filip@meca.omtr.pub.ro; Tel.: +4-021-402-9411 \\ + These authors contributed equally to this work.
}

Academic Editors: Antolin Hernández Battez and Rubén González Rodríguez Received: 4 January 2016; Accepted: 12 April 2016; Published: 21 April 2016

\begin{abstract}
To improve the oil-solubility of nanoparticles, a new technology was used to prepare a kind of lubricant containing titanium dioxide $\left(\mathrm{TiO}_{2}\right)$ nanoparticles. The microstructures of the prepared nanoparticles were characterized via transmission electron microscope (TEM) and infrared spectroscopy (IR). Tribological properties of $\mathrm{TiO}_{2}$ nanoparticles used as an additive in base oil were evaluated using four-ball tribometer and ball-on-disk tribometer. In addition, the worn surface of the steel ball was investigated via polarized microscopy (PM) and X-ray photoelectron spectroscopy (XPS). The $\mathrm{TiO}_{2}$ nanoparticles can be completely well-dispersed in the base oil under a new process (NP), which has no significantly negative effect on the anti-oxidation property. The results of the tribological tests show that $\mathrm{TiO}_{2}$ nanoparticles under the NP show a better anti-wear property and friction-reducing property in base oil compared to $\mathrm{TiO}_{2}$ nanoparticles under the tradition process (TP). The main aim of this paper lies in solving with the oil-solubility problem through the combination effect of surface modification and special blend process of lubricating oil. This method was first used to prepare lubricant containing $\mathrm{TiO}_{2}$ nanoparticles and then used as additives in engine oil, gear oil, and other industrial lubricants. At the same time, tribological properties of $\mathrm{TiO}_{2}$ nanoparticles in base oil as a lubricating additive were also studied.
\end{abstract}

Keywords: blended oil; lubricants; titanium dioxide $\left(\mathrm{TiO}_{2}\right)$ nanoparticles; oil-solubility; tribological properties

\section{Introduction}

Conventional lubricant additives are generally thosecompounds containing sulfur, phosphor, or chlorine, among others [1-3] that play an important role in gear lubrication and cutting lubrication. However, the commercial applications of these kinds of additives are unsatisfactory because of the pungent odor, extreme corrosion, and the poor thermal stability [4-7]. Therefore, it is necessary to develop new kinds of additives that can be used as a substitute for traditional lubricant additives. The use of nanoparticles as oil additives and lubricants is a recent idea. Numerous nanoparticles have been investigated in recent years [8-22]. These oil additives contain small particles of solid material, and their use is not straightforward and only recently has been recognized as feasible. The utilization of oil additives as nanolubricants presents many advantages, as they are relatively insensitive to temperature, and tribochemical reactions are limited, compared to traditional additives. Different anti-friction and anti-wear mechanisms using the nanoparticulate additives have been explained in previous papers $[10,12-14,23,24]$. 
Experimental results with nanoparticles used as additives in oil lubricants show that they deposit on the friction surfaces and improve the tribological properties of the base oil, displaying good friction and wear reduction features, even at low concentrations. Inter alia, titanium dioxide $\left(\mathrm{TiO}_{2}\right)$ nanoparticles as lubricant additive were studied with much more attention, because of their good performance on anti-oxidant features, relatively low toxicity, pleasant odor, and non-volatility [25-27]. Unfortunately, nanoparticles are not well dispersed in nonpolar organic solvents due to their oleo-philic property, which limits the nanoparticles applications in lubricants. Now, two approaches to solve this frequently problem are taken. The first method is the addition of dispersant into base oil. The main drawback of this method is that the sedimentation is unavoidable after a long-time storage and the negative effect of same dispersants on tribological properties [28-31]. The second method is the usage of surfactant [31-33].

Based on what we know metal nanoparticles, oxide nanoparticles and hydrate nanoparticles can change their oil solubility utterly under the effect of surface modification-even transfer from water to oil phase [34,35]. However, titanium (Ti) atoms of $\mathrm{TiO}_{2}$ coordinate with either two or three oxygen atoms $(\mathrm{O})$ to form $\mathrm{TiO}_{2}$ or $\mathrm{Ti}_{2} \mathrm{O}_{3}$ groups, so they are hybridized to a planar or three-dimensional structure. Such structure units can comprise several different typical groups through various combinations, which lead to a structure more complex and cause the difficulty of surface modification of $\mathrm{TiO}_{2}$. However, the transfer and adhesion of the nanoparticles accelerates surface modification, self-reduction, and the formation of a fine $\mathrm{TiO}_{2}$ tribofilm that reduced the coefficient friction, pressure, and temperature in contact area and hence wear. Thus, it can be concluded that both methods (listed above) are classical and have their own defects (the addition of dispersant or usage of surfactant into base oil) for solving the oil solubility of $\mathrm{TiO}_{2}$ nanoparticles. This claim is strengthened by the works of several researchers [3,8-11,23,24,36-38]. Therefore, the application process of the two classical methods was named the traditional process (TP). The $\mathrm{TiO}_{2}$ nanoparticles cannot be well dispersed in the base oil after the TP, for the sedimentation is unavoidable in time, with negative effect on tribological properties.

In this paper, a new preparation method-referred to here as the new process (NP)—is suggested for solving the poor oil solubility of $\mathrm{TiO}_{2}$. The new technology is no longer restricted to the surface modification process, but solves the difficult problem through the combination effect of surface modification and an oil-blending process. The new method was first used to prepare a lubricant containing $\mathrm{TiO}_{2}$ nanoparticles, and it should be helpful for the $\mathrm{TiO}_{2}$ nanoparticles used as additives in engine oil, gear oil, and other industrial lubricants [39-41]. At the same time, tribological properties of $\mathrm{TiO}_{2}$ nanoparticles in base oil as a lubricating additive were also studied. Thus, the paper discusses the anti-friction and anti-wear behavior of $\mathrm{TiO}_{2}$ nanoparticle suspensions in base oil (nanolubricant or nanofluid) under mixed lubrication using a four-ball tribometer and ball-on-disk tribometer, and presents PM and XPS analysis of the worn surfaces.

\section{Experimental Details}

\subsection{Materials, Blend Oil Process, and Characterization}

Oleic acid for chemical industry (Sigma-Aldrich Co. LLC., Wilmington, NC, USA, from office in Germany), absolute ethanol (Sigma-Aldrich Chemie $\mathrm{GmbH}$, Munich, Germany), $\mathrm{TiO}_{2}$ nanoparticles, and petroleum ether $\left(60^{\circ} \mathrm{C}-90^{\circ} \mathrm{C}\right.$, Xilong Chemical Co. Ltd., Guangzhou, Guangdong, China) were of analytical grade. All the reagents were used without further purification. Distilled water was applied for all synthesis and processes. API-1509 base oil came from Petro-Brazi Lubricating Oil R\&D Institute. Its typical properties are given in Table 1. 
Table 1. Properties of the API-1509 base oil.

\begin{tabular}{cc}
\hline Kinematic Viscosity $\left[\mathrm{mm}^{\mathbf{2}} / \mathrm{s}\right]$ to: & $\mathbf{4 2 . 8 5}$ \\
$-\mathbf{4 0} \mathbf{0}^{\circ} \mathbf{C}$ & $\mathbf{6 . 0 3 7}$ \\
$\mathbf{- 1 0 0 ^ { \circ } \mathbf { C }}$ & 80 \\
Viscosity index & -9 \\
Pour point $\left[{ }^{\circ} \mathrm{C}\right]$ & 199 \\
Flash point $\left[{ }^{\circ} \mathrm{C}\right]$ & 0.05 \\
Acid value $[\mathrm{mgKOH} / \mathrm{g}]$ & 0.03 \\
Sulfur content $[\%]$ & 90 \\
Degree of saturation $[\%]$ & Yellowish \\
Color &
\end{tabular}

The typical experimental procedure for preparing surfaces modified particles is as follows: Analytical-grade titanium tetrachloride $\left(\mathrm{TiCl}_{4}\right)$ was adopted as the source material and sodium hydroxide $(\mathrm{NaOH})$ as mineralizer, which by reaction is obtained $\mathrm{TiO}_{2}$. A certain amount of $\mathrm{TiO}_{2}$ (obtained from the reaction $\mathrm{TiCl}_{4}$ and $\mathrm{NaOH}$ ) was first diluted in the mixture solution of absolute ethanol and distilled water. An aqueous solution of $\mathrm{TiO}_{2}$ was obtained by mixing one molar stoichiometric ratio of $\mathrm{TiO}_{2}$ in $50 \mathrm{~mL}$ of distilled water. The aqueous solution with 2-3 mol of $\mathrm{NaOH}$ was stirred for several minutes (5 min), resulting in a white colloidal solution. The final volume was adjusted to $90 \mathrm{~mL}$ using distilled water. Therefore, the $90-\mathrm{mL}$ solution was transferred to a $100-\mathrm{mL}$ Teflon lined auto clave vessel. The sealed vessel was heated to $240{ }^{\circ} \mathrm{C}$ for $12 \mathrm{~h}$, and the resultant precipitate was dried at $450{ }^{\circ} \mathrm{C}$ for $2 \mathrm{~h}$ to obtain $\mathrm{TiO}_{2}$ nanoparticles. Then, $\mathrm{TiO}_{2}$ nanoparticles were mixed with the petroleum ether containing oleic acid and stirred for $2 \mathrm{~h}$ at room temperature. The white liquid suspended matter was dried by the rotary evaporation method, followed by filtering, washing repeatedly with water and absolute ethanol to remove unreacted reactants and oleic acid, followed by drying at $80^{\circ} \mathrm{C}$ for $4 \mathrm{~h}$ with a conventional oven, in an ambient air environment.

A certain amount of prepared $\mathrm{TiO}_{2}$ nanoparticles was added to the base oil. The mixture $\left(\mathrm{TiO}_{2}\right.$ nanoparticles added in base oil) was exposed to direct insert ultrasound irradiation in ambient air for 10 min. Ultrasound irradiation was accomplished with a high-intensity ultrasonic probe (Ti-horn, $25 \mathrm{kHz}$, $1200 \mathrm{~W} / \mathrm{cm}^{2}$ ) immersed directly in the reaction solution. Then, the solution was accomplished in an ultrasonic cleaning bath in ambient air for $15 \mathrm{~min}$. After the above two procedures, the appearance of the base oil with nanoparticles was of semitransparent suspension. It was heated and stirred at $120^{\circ} \mathrm{C}$ for $30 \mathrm{~min}$, followed by cooling and standing. Finally, the transparent stable lubricant was obtained.

All lubricants containing $0.1,0.2,0.3,0.4,0.5 \mathrm{wt} \%$ surface-modified $\mathrm{TiO}_{2}$ nanoparticles were obtained. For comparison, lubricants under the TP of oil-blending were also prepared. The TP by oil-blending used for comparison with the NP is as follows: the insert ultra-irradiation and ultrasonic cleaning bath was used under the same condition as the above. Then, it was heated and stirred at $120^{\circ} \mathrm{C}$ for $30 \mathrm{~min}$, followed by cooling and standing.

It should be noted that heating and stirring were necessary and carried out at the same temperature for both lubricants (NP and TP) to obtain a transparent stable lubricant.

The morphology and size of the samples were observed using a transmission electron microscope (TEM) by type JEM-2100F. The samples for TEM were dispersed in absolute ethanol and ultrasonicated before observation. The adsorption behavior of oleic acid on the $\mathrm{TiO}_{2}$ nanoparticles was characterized with a FTIR spectrometer on a Bio Rad FTS-165. The wave number ranges from 4000 to $500 \mathrm{~cm}^{-1}$ at a resolution of $4 \mathrm{~cm}^{-1}$.

The dispersing stability of lubricant was measured with TG20C high-speed centrifuge, in accordance with previous works [20-22]. The conditions were: 10,000 rpm for $10 \mathrm{~min}$. In total, $10 \mathrm{~g}$ of sample was placed in the centrifuge tube and centrifuged. The centrifuged precipitate was dried in muffle and weighted to the nearest $0.1 \mathrm{mg}$; in the end, the percentage of precipitate was obtained. 
The antioxidation property of lubricant was characterized with a P/N 15300-3 rotating bomb tester by Seta Corporation England. The test temperature was $150^{\circ} \mathrm{C}$. Angulations between bomb and level were $30^{\circ}$, and the rotation speed of bomb was $100 \mathrm{rpm}$.

Tribological properties of $\mathrm{TiO}_{2}$ nanoparticles used as an additive in base oil were evaluated on a four-ball tribometer and a ball-on-disk tribometer, and the worn surface was investigated by polarized microscope (PM) with a Leica DM LP type and with X-ray photoelectron spectroscopy (XPS) on a PHI-5702 electron spectrometer using pass energy of $188 \mathrm{eV}$ and $\mathrm{Mg}$ Ka line excitation source with the reference $\mathrm{C} 1 \mathrm{~s}$ at $284.6 \mathrm{eV}$.

\subsection{Measurement of Anti-Wear and Friction-Reducing Properties, Analysis of the Friction Surface}

Wear tests were carried out with a four-ball tribometer. At the end of each test, the mean wear scar diameter (WSD) on the three down balls was measured using a digital reading optical microscope with an accuracy of $0.01 \mathrm{~mm}$. The steel balls used in the tribological test had a diameter of $12.7 \mathrm{~mm}$ made of Rul2 bearing steel with an HRC of 59-61 hardness. Rul2 bearing steel (which is similar to AISI K 19,195 steel) has a composition according to Table 2.

Table 2. Composition Rul2 (similar to AISI K 19,195) steel.

\begin{tabular}{cccccccc}
\hline Symbol & C [\%] & Si [\%] & Mn [\%] & P [\%] & S [\%] & Cr [\%] & Mo [\%] \\
\hline Rul2 & $0.93-1.05$ & $0.45-0.75$ & $1.00-1.20$ & $\max 0.025$ & $\max 0.015$ & $1.40-1.65$ & $\max 0.10$ \\
\hline
\end{tabular}

The friction coefficient of the oil was measured both with a model based on the principle of reciprocating friction on a ball-on-disk tribometer and with a four-ball tribometer according to ASTM D5183-95. The tribological conditions of model reciprocating friction were: a frequency of $25 \mathrm{~Hz}$, a stroke length of $1 \mathrm{~mm}$, a temperature of $75^{\circ} \mathrm{C}$, an applied load of $100 \mathrm{~N}$, a duration of the test of $30 \mathrm{~min}$. The friction test was conducted in a reciprocating "ball-on-disk" mode, through the oscillation of a Rul2 steel ball $(\Phi 12.7 \mathrm{~mm})$ over a Rul2 steel disk $(\Phi 25 \times 8 \mathrm{~mm})$ in the oil samples being tested. The arithmetic average surface roughness $\left(R_{a}\right)$ of the disk was about $0.016 \mu \mathrm{m}$ with an oscillation of $1 \mathrm{~mm}$ of the ball on disk.

The choice of the contact pair Rul2 against Rul2 is explained by the use of the same material couples in experimental tests, both for four-ball tribometer and for the ball-on-disk tribometer, in order to allow a comparison of the results. The major procedure is as follows:

- $\quad$ First, three $12.7 \mathrm{~mm}$ diameter steel balls are clamped together and covered with $12.7 \mathrm{~mL}$ of OMV oil white 32 oil. The fourth 12.7-mm diameter ball, referred to as the "top ball", is pressed with a force of $400 \mathrm{~N}\left(\mathrm{p}_{\mathrm{c}} \approx 2269.6 \mathrm{~Pa}\right.$ ) into the cavity formed by the three clamped balls and with three points of contact. The temperature of the wear-in lubricant is regulated at $75^{\circ} \mathrm{C}$; then, the top ball is rotated at $600 \mathrm{rpm}(v=1.25 \mathrm{~m} / \mathrm{s})$ for $60 \mathrm{~min}$.

- Second, white oil is discarded and balls cleaned. The WSD on each of the lower three balls is examined. If the wear scars average of the balls is $0.63 \mathrm{~mm} \pm 0.03 \mathrm{~mm}$, then the $12.7 \mathrm{~mL}$ of test fluid is added to the ball cup with the worn-in test balls in place. The temperature of the test lubricant is regulated at $75{ }^{\circ} \mathrm{C}$, and the top ball is rotated at $600 \mathrm{rpm}(v=1.25 \mathrm{~m} / \mathrm{s})$ at $100 \mathrm{~N}$ $\left(\mathrm{p}_{\mathrm{c}}=1429.1 \mathrm{~Pa}\right)$ for $10 \mathrm{~min}$.

- Third, the load is then increased by $100 \mathrm{~N}\left(\mathrm{p}_{\mathrm{c}}=1429.1 \mathrm{~Pa}\right)$ at the end of each successive $10 \mathrm{~min}$ interval. The friction coefficient is measured at the end of each $10 \mathrm{~min}$ interval.

Nota bene: The balls were covered primarily with the base oil and were later added $\mathrm{TiO}_{2}$ nanoparticles, because a comparative analysis of the wear scars morphology of the balls was necessary, lubricated with base oil, and then lubricated with base oil containing nanoparticles $\mathrm{TiO}_{2}$.

The balls after the four-ball test were cleaned using an ultrasonic bath in ligroin (laboratory solvent similarly petroleum ether). Polarized microscope (PM) analysis was performed with a Leica 
DM LP scope. XPS analyses of the elements on the wear scar were conducted on the PHI-5702 electron spectrometer.

\section{Result and Discussion}

\subsection{Structure and the Dispersing Stability of $\mathrm{TiO}_{2}$ Nanoparticles}

Representative TEM images of both kinds of nanoparticles are shown in Figure 1. It can be found that the appearance of pure $\mathrm{TiO}_{2}$ was a hollow sheet with the size of around 100-200 nm (Figure 1a), while the average size of surface-modified nanoparticles and thus the size distribution is in the range of 50-100 nm (Figure 1b). Furthermore, the result indicates that the oil additive can effectively keep $\mathrm{TiO}_{2}$ nanoparticles from agglomeration. This role of oil additive improves oleo-phobic property of the nanoparticles and adapts it for use as lubricant additive.

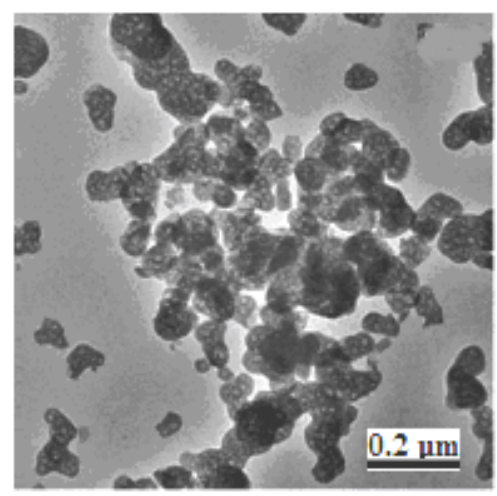

(a)

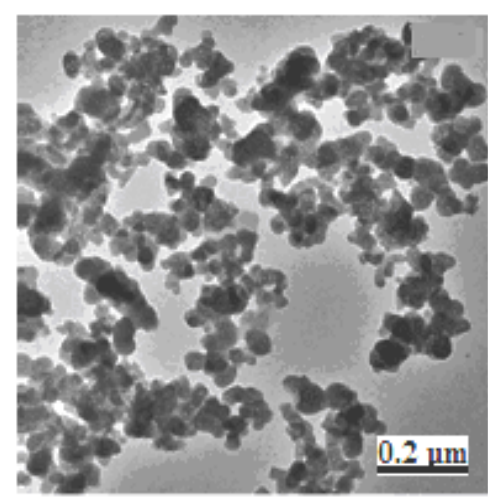

(b)

Figure 1. Transmission electron microscope (TEM) images: (a) of pure titanium dioxide $\left(\mathrm{TiO}_{2}\right)$; (b) of surface-modified $\mathrm{TiO}_{2}$.

To investigate the dispersion stability of nanoparticles under different processes, the centrifuge test was carried out and the oil, containing $\mathrm{TiO}_{2}$ nanoparticles under the NP (coded with (a)) was compared with those containing TiO2 nanoparticles under the TP (coded with (b)). Surface-modified nanoparticles were added into the base oil at a fixed concentration of $0.5 \mathrm{wt} \%$, for both the NP and the TP. No precipitate was detected to the two processes (NP or TP) after the centrifuge test, which indicates that each kind of lubricant has good stability.

The dispersed nanoparticles of $\mathrm{TiO}_{2}$ will start to stabilize (depending on the densities of the $\mathrm{TiO}_{2}$ nanoparticles and the base oil) as soon as the agitation stops, and the dispersion is said to be more or less stable, depending on how long $\mathrm{TiO}_{2}$ nanoparticles remain in suspension. The rate of settling is governed by the density difference between the $\mathrm{TiO}_{2}$ nanoparticles and the base oil, the viscosity of the base oil, and particularly by the size of the $\mathrm{TiO}_{2}$ nanoparticles.

Most commonly the disperse phase $\left(\mathrm{TiO}_{2}\right.$ nanoparticles) is denser than the continuous phase (base oil), and the larger nanoparticles will settle out under the action of gravity soon after agitation stops. The smaller particles will be subject to two influences:

(1) Brownian movement caused by the impact of liquid molecules reduces the effect of gravity so that at a limiting size the nanoparticles will stay in suspension indefinitely.

(2) The surface energy of the solid/liquid interface $\left(\mathrm{TiO}_{2}\right.$ nanoparticles/base oil) increases with decreasing nanoparticle size.

At the same time, the dispersing stabilities of nanoparticles in lubricants also were studied from the aspect of light transmittance (as shown in Figure 2). It is well known that, the better dispersed the nanoparticles in the base oil are, the higher the light transmission of the solution is. It can be seen from 
Figure 2 that the light transmission of lubricant (a) is better than that of lubricant (b). This phenomenon indicates that lubricant (a) has better dispersion stability than lubricant (b). In addition, the lubricant (a) retains clarity, and no sediments were detected after four months.

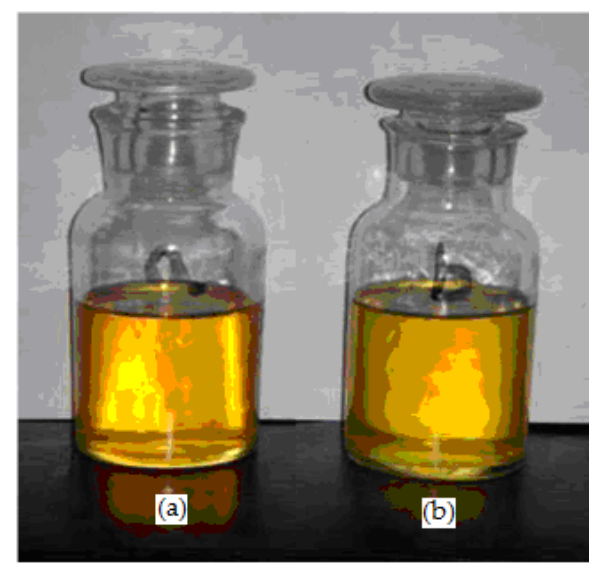

Figure 2. Appearance of (a) lubricant under the NP and (b) lubricant under the TP.

The good dispersing stability of lubricant (a) can be explained by the following:

- $\quad$ First, the effect of surface modification of oleic acid contributes to the good dispersion property.

- Second, weaker agglomerates were grossly eliminated by means of the ultrasound irradiation and direct insert during the novel blending process.

- Third, the higher temperature accelerates the Brownian motion of lubricant, which is helpful to the dispersion of the nanoparticles.

These factors meet the requirements of the dispersing stability of the nanoparticles in the lubricant [26,42]. Eventually, the electric double layer of each nanoparticle formed ensures good dispersing stability of the lubricant. Double-layer electrical charge is formed in the contact areas as a result of electrochemical processes in the early phase of friction operation and as a result of absorption of tensio-active lubricant under the circumstances. Therefore, the base oil containing $\mathrm{TiO}_{2}$ nanoparticles after the NP possesses excellent dispersing stability.

In the blending process after the NP, oils were heated at higher temperature than the usual blending method, and it may influence the anti-oxidation property of the lubricant. To justify the influence, a rotary bomb oxidation test was adopted to evaluate the oxidative stability of lubricant (a) and of the base oil alone. The results show that the time of the rotary bomb oxidation test of the base oil alone is $58 \mathrm{~min}$ and of the base oil containing $\mathrm{TiO}_{2}$ nanoparticles under the NP is 50 min; thus, it can be concluded that the oil blending process under the NP does not have a significant negative effect on the antioxidation property of the base oil.

\subsection{Anti-Wear and Friction-Reducing Properties of $\mathrm{TiO}_{2}$ Nanoparticles}

WSD is an indication of wear extent when sliding contact occurs. WSD results of four-ball tests that were carried out in different oil samples are shown in Figure 3.

Under relatively low concentrations of additive, the WSDs of the base oil slightly increased after adding $\mathrm{TiO}_{2}$ nanoparticles under the NP or the TP; with the increase in additive concentration, WSD of the samples is greatly decreased. The anti-wear property of $\mathrm{TiO}_{2}$ under the NP is better than that of $\mathrm{TiO}_{2}$ under the TP (except for the concentration of $0.1 \mathrm{wt} \%$ ), which can be ascribed to the effect of the good dispersing stability. The exception that occurs at relatively low concentrations of the additive (here of $0.1 \mathrm{wt} \%$ ) seemed to be due to the damming actions of $\mathrm{TiO}_{2}$ nanoparticles accumulated in the front of the leading ball; they were hard to disperse in the base oil and could not easily penetrate into the interface of the base oil and not reduce the shear stress, i.e., no friction force. 


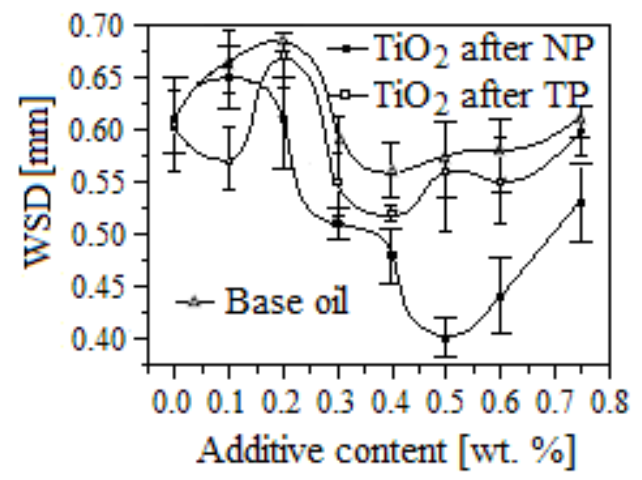

Figure 3. Effect of additive content on the wear scar diameter (WSD), comparative to the base oil under $200 \mathrm{~N}$.

Furthermore, there is an optimum concentration for $\mathrm{TiO}_{2}$ under the NP and the TP corresponding to 0.4 and $0.5 \mathrm{wt} \%$ for their anti-wear abilities. The WSD of the oil containing $\mathrm{TiO}_{2}$ under the NP or the TP increased when the concentration was beyond the optimum concentration. This can be interpreted as granule abrasions that take place in the presence of excess nanoparticles in the friction area $[25,33,39]$. However, it is observed that the anti-wear property of the $\mathrm{TiO}_{2}$ nanoparticles both under the TP and under the NP is better than that of the base oil (see Figure 3). The morphology of the surface is shown in Figure 4, where it can be seen that there are more scratches and deeper scars by the wear due to excess nanoparticles in the friction area (see Figure 4a). Moreover, one can see the difference in surface morphology with the traces of wear scars only in the presence of base oil, as can be seen in Figure $4 b$, where we notice that the wear scars are in sliding direction in the friction zone (approximately parallel).

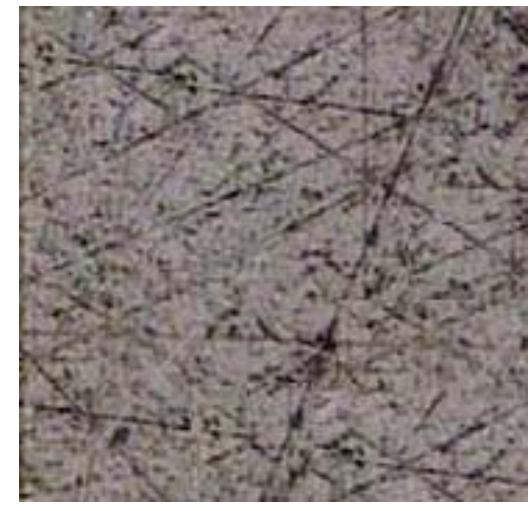

(a)

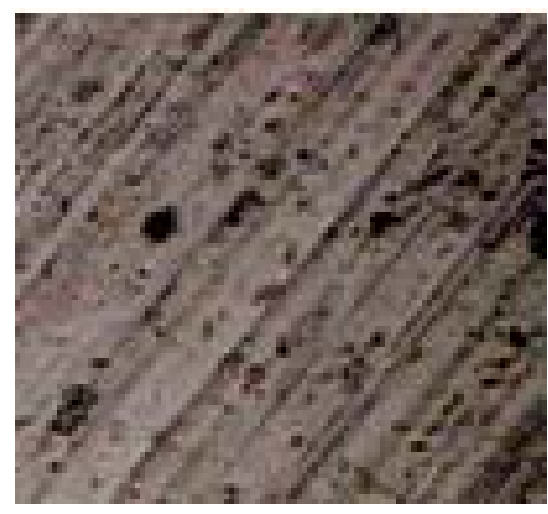

(b)

Figure 4. Morphology of the surface with traces of the abrasion wear in the presence of excess nanoparticles (a) and only of base oil (b) on the friction area.

The friction coefficient is a presentation of energy loss by friction. The results of base oil alone and with oleo-phobic $\mathrm{TiO}_{2}$ are shown in Figures 5 and 6.

As shown in Figure 5, the effect of $\mathrm{TiO}_{2}$ content as an additive in the friction coefficient has the curvilinear trend obtained under the NP similar to that of $\mathrm{TiO}_{2}$ under the TP on the whole, but with different values. Both kinds of additives $\left(\mathrm{TiO}_{2}\right.$ nanoparticles under the NP and the TP) can extraordinarily improve the friction-reducing ability of base oil at the concentration ranging from 0.1 to $0.75 \mathrm{wt} \%$. The friction coefficients of the oils containing $\mathrm{TiO}_{2}$ under the NP or the TP have a steady reduction with the rise in concentration. In addition, the friction-reducing ability of $\mathrm{TiO}_{2}$ under the $\mathrm{NP}$ is better than that of $\mathrm{TiO}_{2}$ under the TP, except for the concentration of $0.1 \mathrm{wt} \%$. Furthermore, 
there is an optimum concentration for the additive under the NP or the TP, which corresponds to a concentration of $0.5 \mathrm{wt} \%$. Furthermore, the minimum friction coefficient of $\mathrm{TiO}_{2}$ after the NP or the TP is 0.115 and 0.120 , respectively. Figure 6 shows the relationship between applied loads and friction coefficients at the same additive concentration of $0.5 \mathrm{wt} \%$. The curvilinear trend of $\mathrm{TiO}_{2}$ under the NP is very similar to that of $\mathrm{TiO}_{2}$ after under the TP. Both lubricants show the highest friction coefficient at an approximate load of $300 \mathrm{~N}$. With an increasing applied load, the friction coefficient gradually becomes smaller.

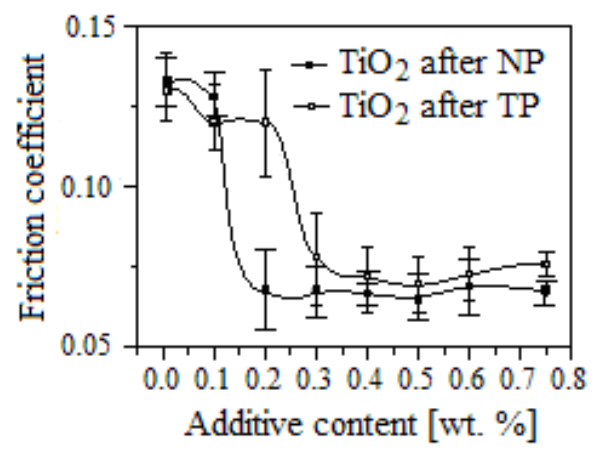

Figure 5. Effect of additive content onfriction coefficient under the ball-on-block tribometer.

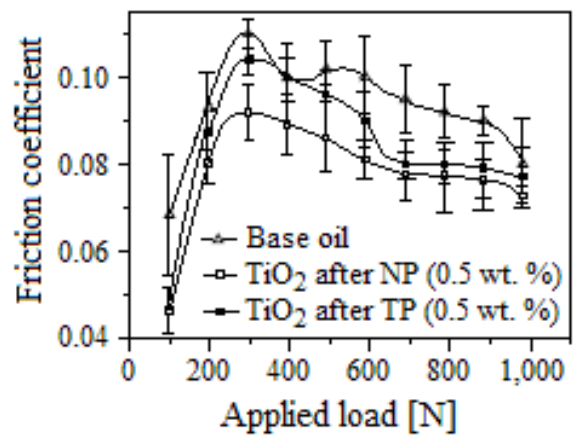

Figure 6. Effect of different loads onfriction coefficient under the four-ball tribometer.

The mechanism of this phenomenon can be explained as follows: the additive film is not formed in the initial stage; resistance at friction is higher, so friction coefficient increases with the increase of the applied load (until $300 \mathrm{~N}$ ). Once some tribochemical reactions have taken place (after $300 \mathrm{~N}$ ), the additive film is formed and resistance at friction gradually decreases, which leads to the slow decrease of friction coefficient. In addition, it is also observed that the friction coefficient of base oil with $\mathrm{TiO}_{2}$ under the NP is better than that of the base oil with $\mathrm{TiO}_{2}$ under the TP (as shown in Figure 5, where the variation of friction coefficient with the load applied to the base oil can be seen).

It can be seen that the base oil containing $\mathrm{TiO}_{2}$ nanoparticles under the NP and the TP provide much lower friction coefficients than that of the base oil. This indicates that $\mathrm{TiO}_{2}$ nanoparticles under the NP and the TP markedly improved the friction-reducing ability of the base oil, which is especially so for the $\mathrm{TiO}_{2}$ nanoparticles under the NP. It can therefore be inferred that $\mathrm{TiO}_{2}$ nanoparticles under the NP favors an enhancement of the friction-reducing ability of $\mathrm{TiO}_{2}$ nanoparticles in the base oil.

Additionally, we observe that, at a low concentration of $\mathrm{TiO}_{2}$ nanoparticles, the base oil reduces the friction coefficients (see Figures 5 and 6) and WSD (see Figure 3) to some extent, and the optimal friction-reducing and anti-wear capacities are obtained at an $\mathrm{TiO}_{2}$ nanoparticles content of $0.5 \mathrm{wt} \%$. However, elevating concentration of $\mathrm{TiO}_{2}$ nanoparticles above $0.5 \mathrm{wt} \%$ leads to an obvious increase in the friction coefficients and WSD, which might be attributed to the agglomeration of $\mathrm{TiO} 2$ nanoparticles under frictional heat [42]. 
Based on the above analysis, it can be deduced that surface-modified $\mathrm{TiO}_{2}$ nanoparticles under the NP possess better anti-wear and friction-reducing ability than that under the TP. These complicated relations may be attributed to not only the presence of Ti in the molecule structure but also the different distribution of $\mathrm{Ti}$ in the lubricant. Two kinds of lubricants have the same quantity of $\mathrm{Ti}$, and the only difference lies in the oil-blending process. Under the NP, surface-modified $\mathrm{TiO}_{2}$ nanoparticles have good dispersing stability in base oil, so it can be supposed that both the presence and the distribution of Ti on the surface play a major role in tribological behavior.

\subsection{Tribological Mechanisms of $\mathrm{TiO}_{2}$ Nanoparticles}

Figure 7 shows the wear scar morphology of the ball lubricated by base oil alone (Figure 7a) and base oil containing $0.5 \mathrm{wt} \% \mathrm{TiO}_{2}$ under the NP (Figure $7 \mathrm{~b}$ ), respectively under the TP (Figure 7c) and under $100 \mathrm{~N}$ using ball-on-disk tribometer.

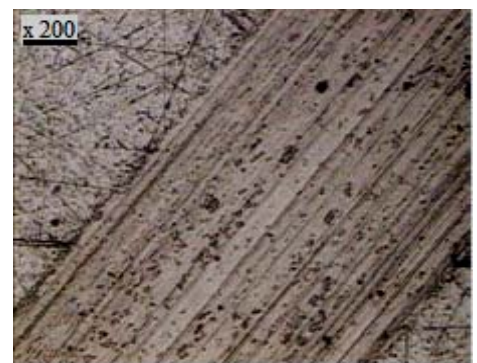

(a)

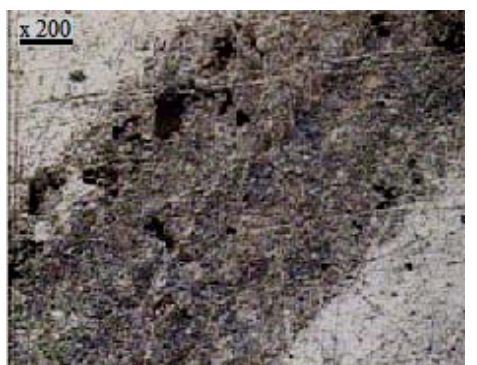

(b)

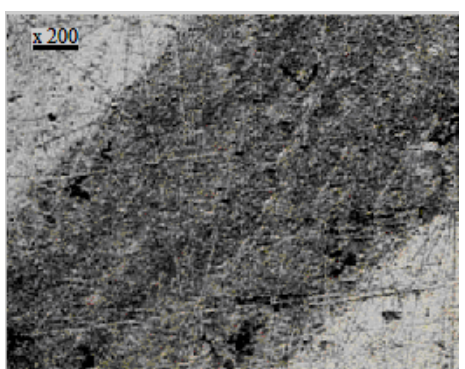

(c)

Figure 7. Micrographs of worn surfaces lubricated by base oil alone (a) and $\mathrm{TiO}_{2}$ nanoparticles under the NP (b) and under the TP (c), respectively, added in oil $(0.5 \mathrm{wt} \%)$.

It can be seen that there are more scratches and deeper furrows on the wear scar obtained from the metal surface lubricated by base oil alone (see Figure 7a) than that of $\mathrm{TiO}_{2}$-added oil under the NP (see Figure 7b) and the TP (see Figure 7c). Through further checks, it is observed that $\mathrm{TiO}_{2}$ both under the NP and the TP play an important role in reducing friction coefficient and improving the anti-wear ability of the base oil; however, that role is more significant under the NP. Therefore, the main role of the NP of oil-blending is to allow the evenly distribution of Ti nanoparticles in the friction area at the time when they are required.

The element composition of wear scar lubricated with base oil containing $0.5 \mathrm{wt} \% \mathrm{TiO}_{2}$ nanoparticles was measured using XPS. Titanium $\left(\mathrm{Ti}_{2 \mathrm{p}}\right)$, oxygen $\left(\mathrm{O}_{1 \mathrm{~s}}\right)$, iron $\left(\mathrm{Fe}_{2 \mathrm{p}}\right)$, and carbon $\left(\mathrm{C}_{1 \mathrm{~s}}\right)$ elements were detected, and the results are shown in Figure 8.

It can be seen that the binding energies of $\mathrm{Ti}_{2 \mathrm{p}}$ locating $464.6\left(\mathrm{Ti}_{2 \mathrm{p} 1 / 2}\right)$ and $458.8\left(\mathrm{Ti}_{2 \mathrm{p} 3 / 2}\right) \mathrm{eV}$ correspond to $\mathrm{Ti}_{2} \mathrm{O}_{3}$ and $\mathrm{Fe}_{2} \mathrm{O}_{3}$, respectively, which suggests that oleo-phobic $\mathrm{TiO}_{2}$ was degraded to $\mathrm{Ti}_{2} \mathrm{O}_{3}$ and reacted with metal surface. The $\mathrm{Ti}_{2 p}$ spectrum mostly appears in the $\mathrm{Ti}^{4+}$ oxidation state with the small contribution of $\mathrm{Ti}^{3+}$. $\mathrm{Ti}^{3+}$ occurs due to oxygen deficiency in the $\mathrm{TiO}_{2}$ lattice [43]. Peak shift is detected, which indicates a decrease of the coordination number of Ti and the shortening of the Ti-O bond. This result supports that the presence of $\mathrm{Ti}^{4+}$ is decreased. The $\mathrm{Ti}_{2 \mathrm{p}}$ peak at $458.8 \mathrm{eV}$ demonstrates that $\mathrm{TiO}_{2}$ is deposited on a worn metal surface. Furthermore, it is clearly seen that $\mathrm{TiO}_{2}$ nanoparticles have a Ti:O ratio different to a pure one. This can be ascribed to a presence of $\mathrm{Fe}_{2 p}$ on the surface of $\mathrm{TiO}_{2}$. The shift of the binding energy resulted from the weak signal because the atomic sensitivity factors of $\mathrm{Ti}_{2 p}$ are much weaker than that of other elements [32], and the peaks cannot be attributed to any other elements $[29,32,39]$. 

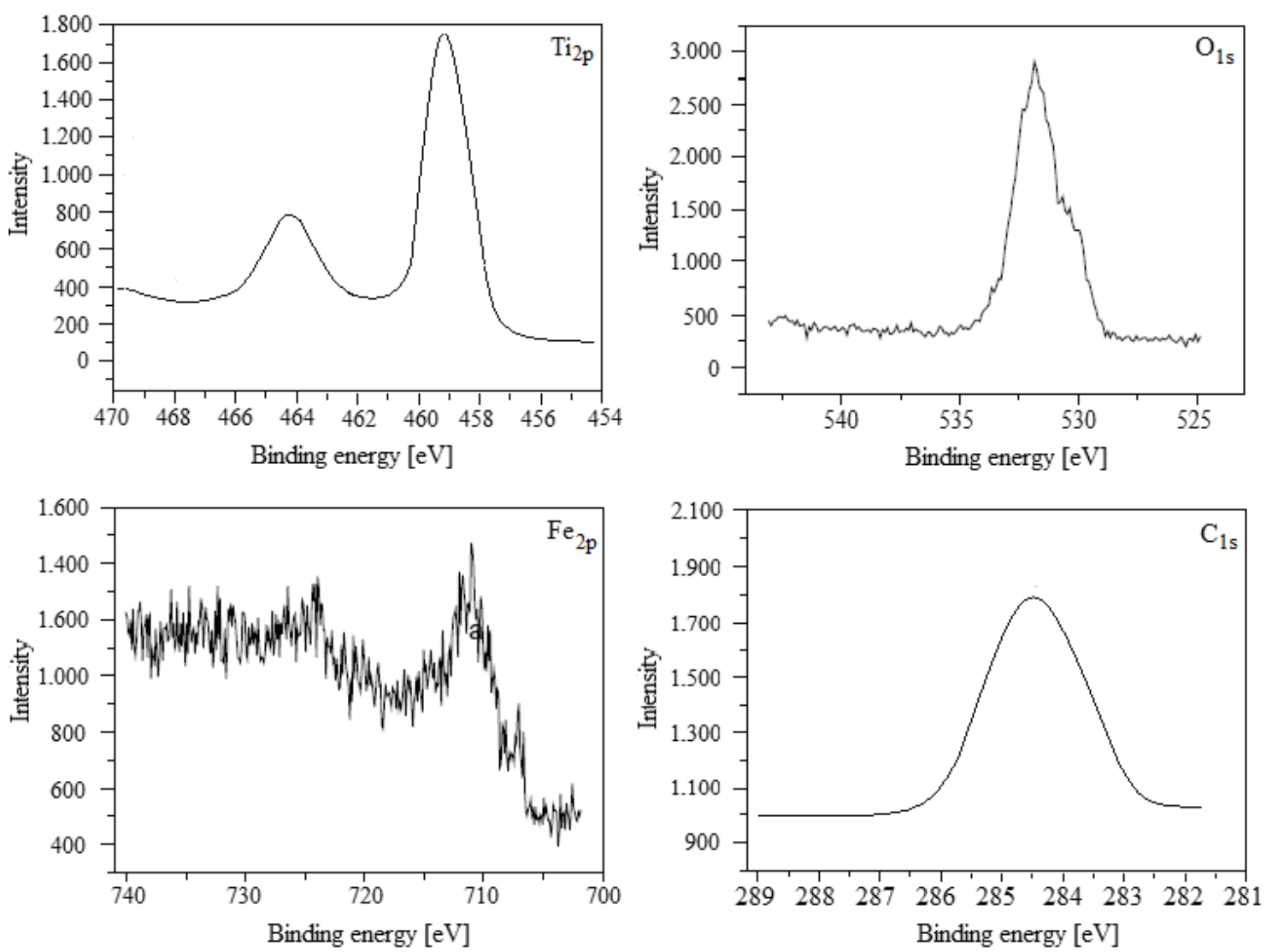

Figure 8. X-ray photoelectron spectroscopy (XPS) of the worn surface.

$\mathrm{The} \mathrm{Ti}_{2 \mathrm{p}}$ peaks are shifted positive from the baseline, indicating a formation of $\mathrm{Fe}-\mathrm{O}-\mathrm{Ti}$ bonds. This can be attributed to the formation of binary $\mathrm{TiO}_{2} / \mathrm{Fe}_{2} \mathrm{O}_{3}$ oxides. $\mathrm{Fe}_{2 p}$ spectra showed a presence of $\mathrm{Fe}^{2+}$ and $\mathrm{Fe}^{3+}$. The binding energy of iron $\left(\mathrm{Fe}_{2 \mathrm{p}}\right)$ locates at 707.1 and $711.2 \mathrm{eV}$, respectively, corresponded to $\mathrm{Fe}^{3+}$ (oxide), i.e. to $\mathrm{Fe}_{2} \mathrm{O}_{3}[30,32,40-42,44]$. $\mathrm{Fe}_{2 p}$ spectra showed a presence of $\mathrm{Fe}^{2+}$ and $\mathrm{Fe}^{3+}$. Peak at $711.2 \mathrm{eV}$ suggests the presence of a minor portion of $\mathrm{Fe}^{2+}$ ions; by exposure, surface $\mathrm{Fe}^{2+}$ lost their electron and changed their ionic state to $\mathrm{Fe}^{3+}$. An $\mathrm{O}_{1 \mathrm{~s}}$ peak appears at $531 \mathrm{eV}$, which is attributed to a signal of oxygen in the $\mathrm{TiO}_{2}$ lattice (Ti-O bonds). It can be seen that the $\mathrm{O}_{1 \mathrm{~s}}$ peak decreased due to the formation of $\mathrm{Fe}-\mathrm{O}$ bonds on the surface of $\mathrm{TiO}_{2}$. Another peak occurred at $531.5 \mathrm{eV}$, which corresponds to the adsorption of OH-group.

The $\mathrm{Fe}_{2 \mathrm{p}}$ peak at $711.2 \mathrm{eV}$ indicates that iron is oxidized into $\mathrm{Fe}_{2} \mathrm{O}_{3}$. Combined with the binding energy of $531.5 \mathrm{eV}$ in $\mathrm{O}_{1 \mathrm{~s}}$ spectra that decreased due to formation of $\mathrm{Fe}-\mathrm{O}$ bonds on the surface of $\mathrm{TiO}_{2}$ and it could be further ascertained that $\mathrm{Fe}_{2} \mathrm{O}_{3}$ must be produced. The $\mathrm{O}_{1 \mathrm{~s}}$ peak at $531.5 \mathrm{eV}$ and the $\mathrm{C}_{1 \mathrm{~s}}$ peak at $288.5 \mathrm{eV}$ reveal and the existence of carbonyl group, and can be explained by the high content of carbon absorbed from the air.

From the above analysis, we can reasonably infer that the friction-reducing and anti-wear mechanisms of the $\mathrm{TiO}_{2}$ nanoparticles under the NP in base oil are mainly attributed to two aspects. First, oleic acid can be physically and chemically adsorbed on the sliding metal surfaces to form an adsorption film, thereby reducing friction and wear of the metal sliding pair. Second, a complex boundary lubrication film mainly composed of oxides of iron and titanium is formed on worn metal surfaces through tribochemical reaction, which also accounts for reduced friction and wear of the metal sliding pair.

Thus, it can be concluded that tribological reaction occurred between surface-modified $\mathrm{TiO}_{2}$ nanoparticles and the metal surface during the sliding process, accompanied by the adsorption of 
decomposed nanoparticles. Both these depositions and tribochemical reaction products $\left(\mathrm{Ti}_{2} \mathrm{O}_{3}, \mathrm{Fe}_{2} \mathrm{O}_{3}\right)$ mainly function with the good tribological properties of surface-modified $\mathrm{TiO}_{2}$ nanoparticles.

\section{Conclusions}

- Nanoparticles are not well dispersed in nonpolar organic solvents due to their oleo-philic property, which limits their applications in lubricant oils. A new technology for improving the poor oil solubility of $\mathrm{TiO}_{2}$ nanoparticles in base oil is thus suggested.

- Nanoparticles added in oil possessing excellent dispersing stability were obtained under the new technology. The nanoparticle suspensions tested exhibited reductions of friction and wear compared to the base oil. $\mathrm{TiO}_{2}$ suspensions under the NP and under the TP presented similar friction and wear behavior as a function of nanoparticle content. Such research might be helpful to overcome the difficulty of the usage of $\mathrm{TiO}_{2}$ nanoparticles in gear lubrication and cutting lubrication.

- The obtained results indicate that the average size of the prepared nanoparticles is in range of 50-100 nm, and the surface of the nanoparticles was altered from oleo-philic to oleo-phobic. In addition, the nanoparticles can be well dispersed in the base oil totally under the NP, which has no significantly negative effect on the anti-oxidation property.

- The results of the tribological experiments indicate that $\mathrm{TiO}_{2}$ nanoparticles under the NP show friction-reducing and better anti-wear property in the base oil compared to $\mathrm{TiO}_{2}$ nanoparticles under the TP.

- Based on the results of PM and XPS, it can be deduced that a continuous resistance film containing depositions and the tribochemical reaction products such as $\mathrm{Ti}_{2} \mathrm{O}_{3}$ and $\mathrm{Fe}_{2} \mathrm{O}_{3}$ formed during the sliding process lead to excellent tribological properties of the nanoparticles in the base oil.

- The main aspect of the novelty of this research lies in dealing with the oil-solubility problem through the combination effect of surface modification and special blend process of lubricating oil, and this method was first used to prepare lubricants containing $\mathrm{TiO}_{2}$ nanoparticles. It should be helpful for the $\mathrm{TiO}_{2}$ nanoparticles used as additives in engine oil, gear oil, and other industrial lubricants.

Author Contributions: Filip Ilie and Cristina Covaliu conceived and designed the experiments; Filip Ilie performed the experiments; Filip Ilie analyzed the data; Cristina Covaliu contributed materials, prepared solutions, and analysis tools; Filip Ilie wrote the paper.

Conflicts of Interest: The authors declare no conflict of interest.

\section{References}

1. Ponomarenko, A.G.; Burlov, A.S.; Boiko, M.V.; Shiryaeva, T.A.; Kalmykova, A.G.; Zaichenko, S.B.; Milutka, M.S. Investigation of tribochemical processes in lubricating compositions that contain coordination compounds of transition metals. J. Frict. Wear 2015, 36, 15-22. [CrossRef]

2. Ilie, F. Energy Dissipation during Adhesion and Friction at the Atomic Scale of $\mathrm{MoS}_{2}$ Nanoparticles on the Surface of $\mathrm{MoS}_{2}$. J. Adv. Microsc. Res. 2013, 8, 270-275. [CrossRef]

3. Zhang, Z.J.; Simionesie, D.; Schaschke, C. Graphite and Hybrid Nanomaterials as Lubricant Additives. Lubricants 2014, 2, 44-65. [CrossRef]

4. Nagendramma, P. Study of pentaerythritol tetraoleate ester as industrial gear oil. Lubr. Sci. 2011, 23, 355-362. [CrossRef]

5. Gili, F.; Igartua, A.; Luther, R.; Woydt, M. The impact of biofuels on engine oil performance. Lubr. Sci. 2011, 23, 313-330. [CrossRef]

6. Ilie, F.; Covaliu, C.; Chişiu, G. Tribological Study of Ecological Lubricants Containing Titanium Dioxide Nanoparticles. Appl. Mech. Mater. 2014, 658, 323-328. [CrossRef] 
7. Hao, L.; Jiang, Z.; Cheng, X.; Zhao, J.; Wei, D.; Jiang, L.; Luo, S.; Luo, M.; Ma, L. Effect of extreme pressure additives on the deformation behavior of oxide scale during the hot rolling of ferritic stainless steel strips. Tribol. Trans. 2015, 58, 947-954. [CrossRef]

8. Yousefpour, M.; Rahimi, A. Characterization and Selection of Optimal Parameters to Achieve the Best Tribological Performance of the Electrodeposited Cr Nanocomposite Coating. Mater. Des. 2014, 54, 382. [CrossRef]

9. Hernández Battez, A.; Viesca, J.L.; González, R.; García, A.; Reddyhoff, T.; Higuera-Garrido, A. Effect of Shear Rate, Temperature, and Particle Concentration on the Rheological Properties of $\mathrm{ZnO}$ and $\mathrm{ZrO}_{2} \mathrm{Nanofluids}_{\text {. }}$ Tribol. Trans. 2014, 57, 489. [CrossRef]

10. Hernández Battez, A.; Viesca, J.L.; González, R.; Blanco, D.; Asedegbega, E.; Osorio, A. Friction Reduction Properties of a CuO Nanolubricant Used as Lubricant for a NiCrBSi Coating. Wear 2010, 268, 325. [CrossRef]

11. Reijnders, L. The Release of $\mathrm{TiO}_{2}$ and $\mathrm{SiO}_{2}$ Nanoparticles from Nanocomposites. Polym. Degrad. Stab. 2009, 94, 873. [CrossRef]

12. Hernández Battez, A.; Viesca, J.L.; González, R.; Fernández, J.E.; Diaz Fernández, J.M.; Machado, A.; Chou, R.; Riba, J. CuO, $\mathrm{ZrO}_{2}$ and $\mathrm{ZnO}$ nanoparticles as antiwear additive in oil lubricants. Wear 2008, 265, 422. [CrossRef]

13. Hernández Battez, A.; González, R.; Felgueroso, D.; Fernández, J.E.; del Rocío Fernández, Ma.; García, M.A.; Peñuelas, I. Wear prevention behaviour of nanoparticle suspension under extreme pressure conditions. Wear 2007, 263, 1568-1574. [CrossRef]

14. Hernández Battez, A.; Fernandez Rico, J.E.; Navas Arias, A.; Viesca Rodriguez, J.L.; Chou Rodriguez, R.; Diaz Fernandez, J.M. The tribological behaviour of $\mathrm{ZnO}$ nanoparticles as an additive to PAO6. Wear 2006, 261, 256-263. [CrossRef]

15. Bakunin, B.N.; Kuzmina, G.N.; Kasrai, M.; Parenago, O.P.; Bancroft, G.M. Tribological behavior and tribofilm composition in lubricated systems containing surface-capped molybdenum sulfide nanoparticles. Tribol. Lett. 2006, 22-23, 289-296. [CrossRef]

16. Gao, Y.; Chen, G.; Oli, Y.; Zhang, Z.; Xue, Q. Study on tribological properties of oleic acid-modified $\mathrm{TiO}_{2}$ nanoparticle in water. Wear 2002, 252, 454-458. [CrossRef]

17. Zhou, J.; Wu, Z.; Zhang, Z.; Liu, W.; Dang, H. Study on an antiwear and extreme pressure additive of surface coated $\mathrm{LaF}_{3}$ nanoparticles in liquid paraffin. Wear 2001, 249, 333-337. [CrossRef]

18. Qiu, S.; Zhou, Z.; Dong, J.; Chen, G. Preparation of Ni nanoparticles and evaluation of their tribological performance as potential additives in oils. J. Tribol. 2001, 123, 441-443. [CrossRef]

19. Dong, J.X.; Chen, G.; Qiu, S. Wear and friction behaviour of $\mathrm{CaCO}_{3}$ nanoparticles used as additives in lubricating oils. Lubr. Sci. 2000, 12, 205-212.

20. Hu, Z.S.; Dong, J.X.; Chen, G.X.; He, J.Z. Preparation and tribological properties of nanoparticle lanthanum borate. Wear 2000, 243, 43-47. [CrossRef]

21. Hu, Z.S.; Dong, J.X. Study on antiwear and reducing friction additive of nanometer titanium borate. Wear 1998, 216, 87-91. [CrossRef]

22. Hu, Z.S.; Dong, J.X. Study on antiwear and reducing friction additives of nanometer titanium oxide. Wear 1998, 216, 92-96. [CrossRef]

23. Chinas-Castillo, F.; Spikes, H.A. Mechanism of action of colloidal solid dispersions. J. Tribol. Trans. ASME 2003, 125, 552-557. [CrossRef]

24. Wu, Y.Y.; Tsui, W.C.; Liu, T.C. Experimental analysis of tribological properties of lubricating oils with nanoparticle additives. Wear 2007, 262, 819. [CrossRef]

25. Johnson, D.W.; Bachus, M.; Hils, J.E. Interaction between Lubricants Containing Phosphate Ester Additives and Stainless Steels. Lubricants 2013, 1, 48-60. [CrossRef]

26. Asadauskas, S.J.; Brazinskiene, D.; Bikulcius, G.; Kreivaitis, R.; Padgurskas, J. Surfactant Influence on Stability and Lubrication Properties of Metal Nanoparticle Suspensions in Oil. In Surfactants in Tribology; Biresaw, G., Mittal, K.L., Eds.; CRC Press, Taylor \& Francis Group: New York, NY, USA, 2014; Volume 4, pp. 150-189.

27. Tuszynski, W.; Szczerek, M.; Michalczewski, R.; Osuch-Slomka, E.; Rogos, E.A. The potential of the application of biodegradable and non-toxic base oils for the formulation of gear oils-Model and component scuffing tests. Lubr. Sci. 2014, 26, 327-346. [CrossRef] 
28. Li, W.; Wu, Y.; Wang, X.; Liu, W. A study of P-N compound as multifunctional lubricant additive. Lubr. Sci. 2011, 23, 363-373. [CrossRef]

29. Zhao, G.; Zhao, Q.; Li, W.; Wang, X.; Liu, W. Tribological properties of nano-calcium borate as lithium grease additive. Lubr. Sci. 2014, 26, 43-53. [CrossRef]

30. Padgurskas, J.; Rukuiza, R.; Prosycevas, I. Tribological properties of lubricantadditivesof Fe, Cu and Conanoparticles. Tribol. Int. 2013, 60, 224-232.

31. Xue, M.-Q.; Tang, H.; Li, C.-S. Synthesis and tribological properties of TiC micro and nanoparticles. Int. J. Surf. Sci. Eng. 2015, 9, 69-80. [CrossRef]

32. Zaimovskaya, T.A.; Oganesova, E.Y.; Kuzmina, G.N.; Ezhov, A.A.; Ivanov, V.K.; Parenago, O.P. Titanium-containing compounds as efficient triboadditives to oils. J. Frict. Wear 2013, 34, 487-493. [CrossRef]

33. Zhao, C. The Influence of Solid Additives on the Tribological Properties of Lubricants. PhD Thesis, University of Hertfordshire, Hatfield, UK, 27 June 2013.

34. Xue, M.; Tang, H.; Song, H.; Li, C. Preparation and tribological properties of nanoaluminium fluoride as additives to base oil. Micro Nano Lett. 2014, 9, 225-228. [CrossRef]

35. Zhang, W.; Zhou, M.; Zhu, H.; Tian, Y.; Wang, K.; Wei, J.; Ji, F.; Li, X.; Li, Z.; Zhang, P. Tribological properties of oleic acid-modified graphene as lubricant oil additives. J. Phys. D Appl. Phys. 2011, 44, 205303. [CrossRef]

36. Zhang, L.; Chen, L.; Wa, H.; Chen, J.; Zhou, H. Synthesis and tribological properties of stearic acid-modified anatase $\left(\mathrm{TiO}_{2}\right)$ nanoparticles. Tribol. Lett. 2011, 41, 409-416. [CrossRef]

37. Lee, K.; Hwang, Y.; Cheong, S.; Choi, Y.; Kwon, L.; Lee, J.; Kim, S.H. Understanding the role of nanoparticles in nano-oil lubrication. Tribol. Lett. 2009, 35, 127-131. [CrossRef]

38. Xue, Q.; Liu, W.; Zhang, Z. Friction and wear properties of a suface-modified $\mathrm{TiO}_{2}$ nanoparticle as an additive in liquid paraffin. Wear 1997, 213, 29. [CrossRef]

39. Huang, Y.; Han, S.; Liu, S.; Wang, Y.; Li, J. Preparation and tribological properties of surface-modified calcium borate nanoparticles as additive in lubricating oil. Ind. Lubr. Tribol. 2014, 66, 143-150. [CrossRef]

40. Ingole, S.; Charanpahari, A.; Kakade, A.; Umare, S.S.; Bhatt, D.V.; Menghani, J. Tribological behavior of nano $\mathrm{TiO}_{2}$ as an additive in base oil. Wear 2013, 301, 776. [CrossRef]

41. Gu, Y.; Zhao, X.; Liu, Y.; Lv, Y.X. Preparation and Tribological Properties of Dual-Coated $\mathrm{TiO}_{2}$ Nanoparticles as Water-Based Lubricant Additives. J. Nanomater. 2014. [CrossRef]

42. Qian, J.H.; Yin, X.Y.; Wang, N.; Liu, L.; Xing, J.J. Preparation and tribological properties of stearic acid-modified hierarchical anatase $\mathrm{TiO}_{2}$ microcrystals. Appl. Surf. Sci. 2011, 258, 2278. [CrossRef]

43. Bapna, K.; Phase, D.M.; Choudhary, R.J. Study of valence band structure of Fe doped anatase $\mathrm{TiO}_{2}$ thin films. J. Appl. Phys. 2011, 110. [CrossRef]

44. Bakunin, V.N.; Suslov, A.Y.; Kuzmina, G.N.; Parenago, O.P. Recent achievements in the synthesis andapplication of inorganic nanoparticles as lubricant components. Lubr. Sci. 2005, 127, 127-145. [CrossRef] 